\title{
Proceeding
}

7th INSHS International Christmas Sport Scientific Conference, 9-12 December 2012. International Network of Sport and Health Science. Szombathely, Hungary

\section{Video analysis applied to volleyball didactics to improve sport skills}

\author{
GAETANO RAIOLA , FABIO PARISI, YLENIA GIUGNO, PIO ALFREDO DI TORE, \\ Department of Human, Philosophical and Education Sciences (DISUFF) University of Salerno, Italy
}

\begin{abstract}
Raiola G, Parisi F, Giugno Y, Di Tore PA. Video analysis applied to volleyball didactics to improve sport skills. J. Hum. Sport Exerc. Vol.8, No. Proc2, pp. S307-S313, 2013. The feedback method is increasingly used in learning new skills and improving performance. "Recent research, however, showed that the most objective and quantitative feedback is, the ${ }^{\circ}$ greater its effect on performance". The video analysis, which is the analysis of sports performance by watching the video, is used primarily for use in the quantitative performance of athletes through the notational analysis. It may be useful to combine the quantitative and qualitative analysis of the single gesture for use in technical training in real time. Currently there are no specific studies on volleyball on the use of performance analysis during training. The scope of work is to carry out a preliminary study on the use of video analysis in volleyball recruiting quantitative and qualitative data to build a model to describe executive motor and propose a total athlete and analytically for each athletic ability. This training method is part of the planning of educational training to improve the performance of athletes. Using video analysis of technical movements of the attack, carried by four athletes in training, the category under 13 years old, which will be compared to a video-execution model of reference. The benchmarks are: Optimum preparation for the strike on the ball and angle of the body with the floor; Horizontal Speed and Step Length (left foot); 2 Next Steps (right-left), and their length, angle of the arms; Phase Out, hit the ball and reached the heights from knee and hand; fallout on the ground with both feet. The four athletes will be divided into two groups of two people: Both group A, the control group, than the B group, the experimental group, will be filmed at the beginning and end of the project, and every day in training, both groups following the same training program, for 30 meetings. Group $A$ will not be provided feedback during the course of their performance, while group B will be offered every day, the video of the execution of the fundamental attack took place during the previous exercise. At the end of the research, comparison will be made between the beginning and end of video and educational activities between the control group and the experimental group for each training done, to verify the improvements, to note the differences between the groups. The differences in the comparison of results will contribute to the choice of this method in training and possibly deepen the issue in other ways. Key words: PERFORMANCE ANALYSIS, VIDEO ANALYSIS, SPORTS SKILLS.
\end{abstract}

Corresponding author. Gaetano Raiola, Via Berenice 11, Napoli, Italy.

Email: raiolagaetano@libero.it

7th INSHS International Christmas Sport Scientific Conference, 9-12 December 2012. International Network of Sport and Health Science. Szombathely, Hungary.

JOURNAL OF HUMAN SPORT \& EXERCISE ISSN 1988-5202

(c) Faculty of Education. University of Alicante

doi:10.4100/jhse.2012.8.Proc2.33

VOLUME 8 | Proc2 | 2013| S307 


\section{INTRODUCTION}

The process of training plays a vital role in performative sports and can be described as the relationship between the coach and the athlete who has the purpose of facilitating an improvement in athletic performance (Lyle, 2002).

Hughes (2005) states that, in many team sports, it is difficult for an observer to see and assimilate all the action taking place on the competition. It was noted that, because of coaches who are able to see only those phases of the game related to a specific stage, the most peripheral part of the game is lost. So often, coaches are limited to base their feedback after the race on partial information of the performance of the team or of individual athletes.

Recent research, however, showed that the most objective and quantitative feedback is, the greater is its effect on performance. The video analysis, which is the analysis of sports performance by watching the video, is used primarily for use in the quantitative performance of athletes through the notational analysis (Hughes \& Frank).

It may be useful to combine the quantitative and qualitative analysis of the individual technical movements (Tavares et al) for use in real-time training, knowing that "tactical and technical aspects assume greater importance than quantity in volleyball" (Raiola \& Di Tore, 2012a, 2012b). Currently there are no specific studies on volleyball about the use of performance analysis during training. The scope of practice is to carry out a preliminary study on the use of video analysis in volleyball recruiting quantitative and qualitative data to build a model to describe executive motor and propose for each athlete athletic ability. This training method is part of the planning of educational training to improve the performance of athletes.

The aim of this study is to initiate a search in Volleyball, which may include the use of video analysis and performance analysis to analyze and describe the "quantity and quality" of technical movements, to teach the fundamentals, in training. The purpose is to improve the performance of our athletes through an innovative learning, using visual feedback.

The project is as a result of a previous work on video analysis in training presented at the 5th Annual International Conference: Physical Education Sport \& Health, the 22nd-23rd of November 2012, in Pitesti, Romania. The project involved 10 athletes, under 13, filmed at the beginning and end of the project (duration: 30 days) in which it was presented a video of the execution model gesture attack before every workout (Figure 1). The results were evident and very rapid. The lack of a control group, however, does not fully understood which have actually been improvements due to the video analysis, and how much is due to the simple execution of exercises done during the 30 days of the project. 


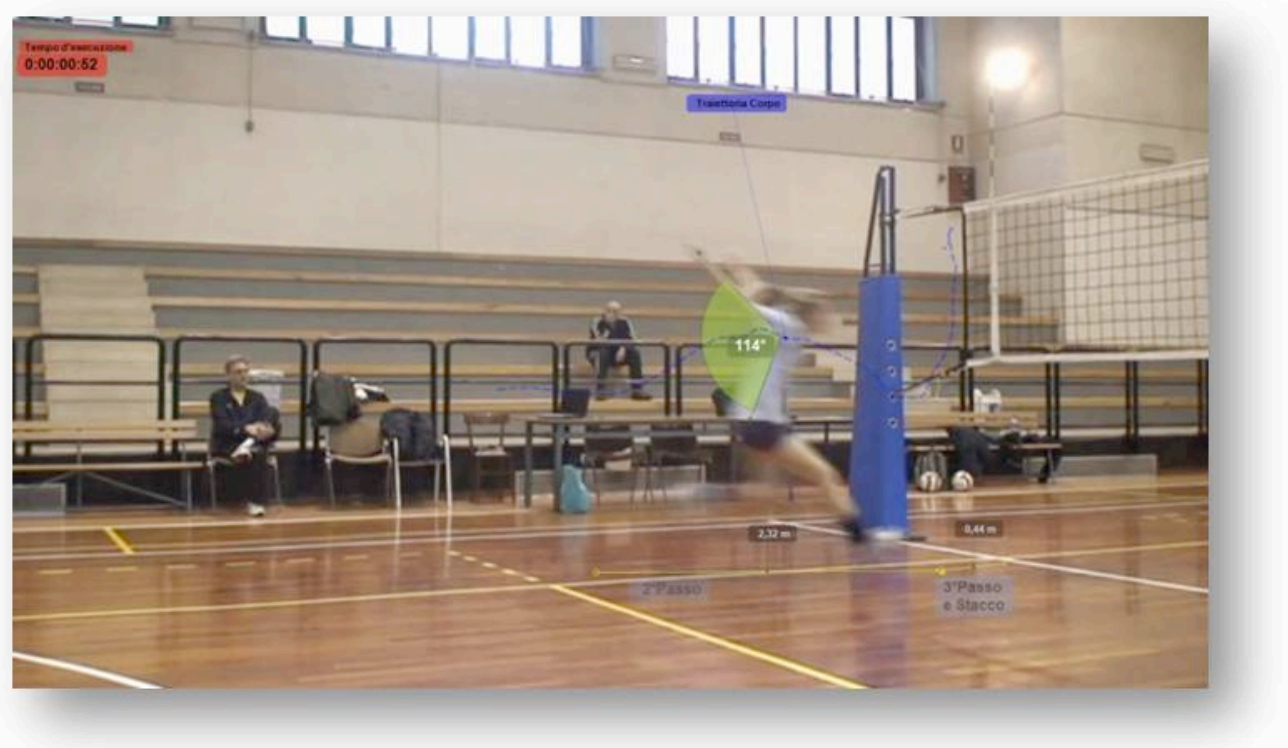

Figure 1. For this reason, it comes the new project, more complex and extended in its form.

\section{MATERIAL AND METHODS}

The pilot study involves the use of video analysis of technical movements of the attack, carried by four male athletes in training, the category under 13 , which will be compared to a video-execution model of reference. The parameters of comparison, detailed in the next section, are: Optimum preparation for the strike on the ball and angle of the body with the floor; Horizontal Speed and Step Length (left foot); 2 Next Steps (rightleft), and their length, angle arms, phase jump, hit the ball with air phase and reached its heights from knee and hand, fallout on the ground with both feet.

The four athletes will be divided into two groups of two people: Both group $A$, the control group, than $B$ group, the experimental group, will be filmed at the beginning and end of the project, and every day in training, they both follow the same training program, for 30 meetings. Group A will not be provided feedback during the course of their performance, while group $B$ will be offered the video of the execution of the fundamental attack took place during the previous exercise every day.

At the end of the project, it will carry out the comparison video between start and end project (Figure 2 and Figure 3), and between the control group and the experimental group for each training done, so as to verify the improvements of the performance, for record the differences between the groups and Furthermore, to get feedback on the effectiveness of a qualitative feedback in training. 


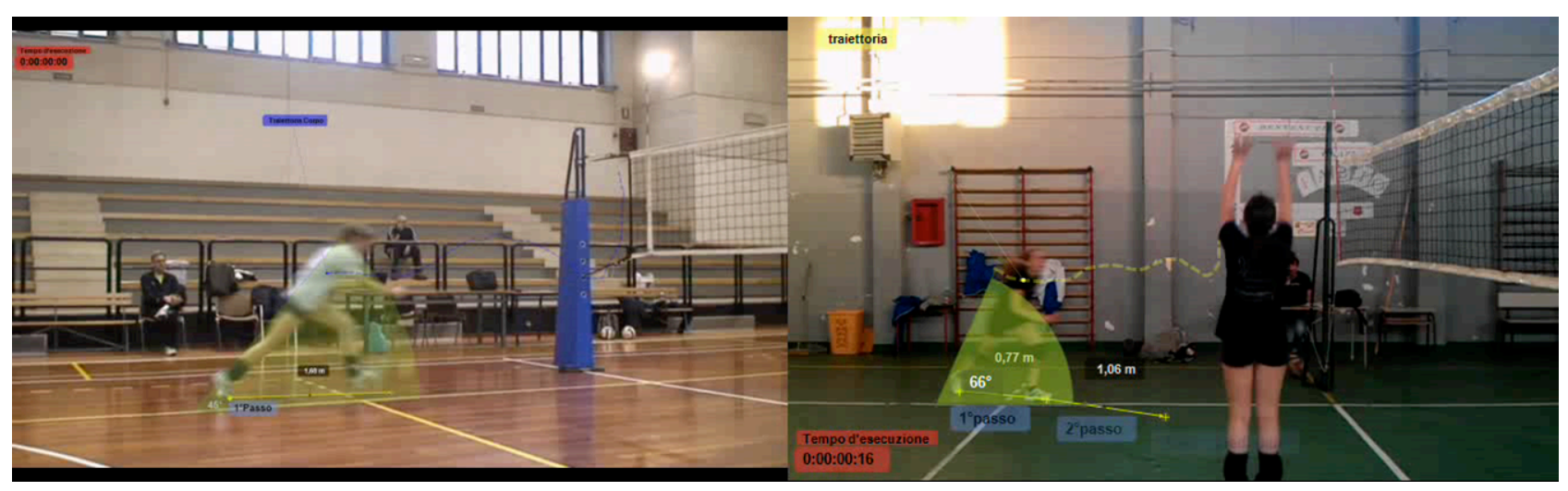

Figure 2. Start and end project a

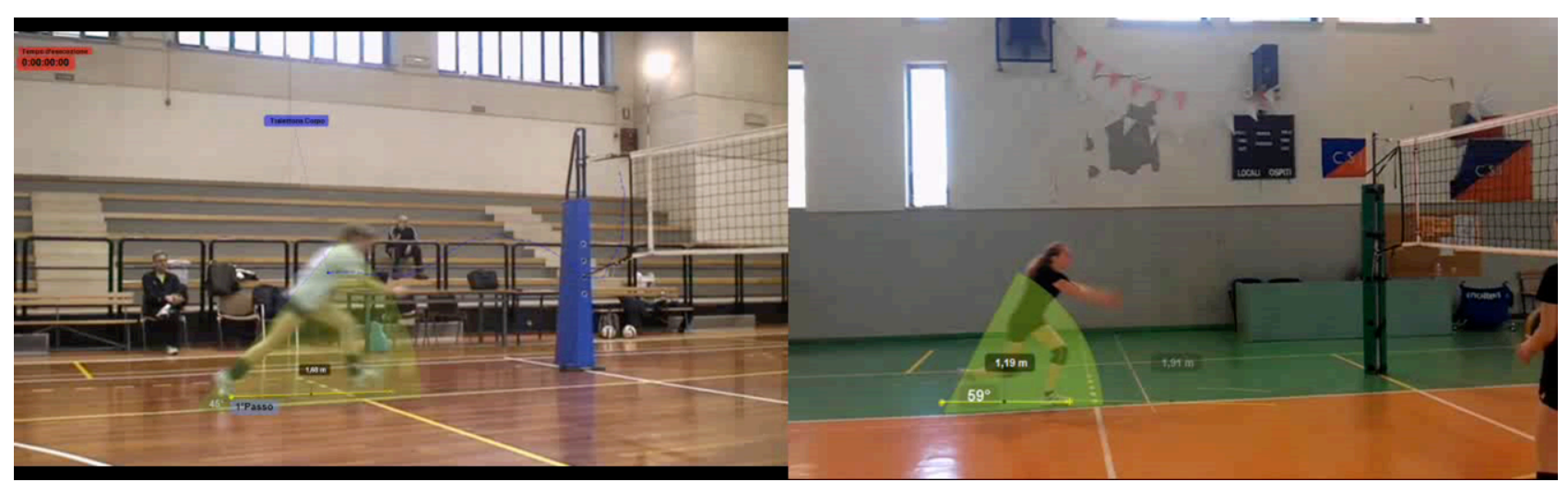

Figure 3. Start and end project ${ }^{b}$

In addition, thanks to the software used, quantitative data will be extrapolated performance, entered in an Excel table (Table 1,2 y 3), and compared to those of the previous project.

Parameters of the fundamental searches in video

The attack consists of a sequence of elements: Preparation and research of the ball, Detach, hit on the ball, run, Phase air fallout.

Optimum preparation for the strike on the ball, angle of the body with the floor:

It's everything before the run. It is precisely position the body in the optimum condition in relation to the trajectory of the ball, in order to be able to make the run more effective. Being able to hit the ball maximizing the acceleration given by a good run and the force of the hit of the hand is only possible if "we start" and "jump" the right instant. 
Table 1, 2 y 3. Quantitative data

KATERINA

\begin{tabular}{rr}
\multicolumn{2}{c}{ Distanze } \\
\hline Length $(\mathrm{m})$ & \multicolumn{1}{c}{ Time } \\
1,68 & $1^{\circ}$ passo \\
2,32 & $2^{\circ}$ passo \\
0,44 & $3^{\circ}$ passo \\
2,57 & altezza spalla \\
1,44 & altezza ginocchio
\end{tabular}

Angoli

Value

$45^{\circ} \quad$ angolo corpo

$114^{\circ}$ Angolo braccia

Tempo d'esecuzione

Duration

0:00:01:68

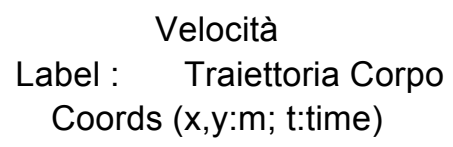

$\mathrm{x}$

vel

\section{MARA (INIZIO)}

\begin{tabular}{rr}
\multicolumn{2}{c}{ Distanze } \\
\hline Length $(\mathrm{m})$ & \multicolumn{1}{c}{ Time } \\
0,77 & $1^{\circ}$ passo \\
1,06 & $2^{\circ}$ passo \\
$?$ & $3^{\circ}$ passo \\
1,6 & altezza spalla \\
0,72 & altezza ginocchio
\end{tabular}

Angoli

Value

$\begin{array}{rr}66^{\circ} & \text { angolo corpo } \\ 0^{\circ} & \text { Angolo braccia }\end{array}$

Tempo d'esecuzione

Duration

0:00:02:08

Velocità

Label : traiettoria corpo

Coords (x,y:m; t:time)

$\mathrm{x}$ vel

1,72

1,54

1,72

1,92

2,1

1,97

1,5

\section{MARA (FINE)}

\begin{tabular}{rr}
\multicolumn{2}{c}{ Distanze } \\
\hline Length $(\mathrm{m})$ & \multicolumn{1}{c}{ Time } \\
1,19 & $1^{\circ}$ passo \\
1,9 & $2^{\circ}$ passo \\
0,42 & $3^{\circ}$ passo \\
2,1 & altezza spalla \\
1,13 & altezza ginocchio
\end{tabular}

Angoli

$$
\begin{array}{rr}
\text { Value } & \\
59^{\circ} & \text { angolo corpo } \\
150^{\circ} & \text { Angolo braccia }
\end{array}
$$

Tempo d'esecuzione

Duration

0:00:01:58

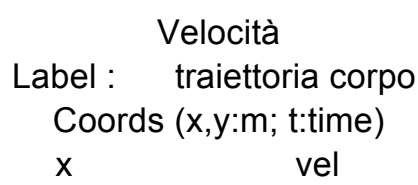

2,23

Horizontal speed, step length (left foot) and the next two steps, angle of the arms:

It's the time when you give horizontal speed to the body. This speed must be as high as possible, but not so high as to cause a loss of coordination of postural control. The run usually starts for a spiker with the forward movement of the right foot with a short step and relatively slow followed by a longer wheelbase and fast, followed by an oblique jump, long and fast where the right and left foot come in succession on the ground, with the left one slightly more advanced to get a better balance.

Phase of detachment:

It's the movement in which the acceleration produced by the running start is verticalized and transformed into jumping ability. The detachment is best achieved when you have the support of an advance on the ground of the heel. The center of gravity of the body is in the retracted position and then lowered slightly to 
be projected upwards in the movement in which the foot performs the rolled, also as a result of contemporary impulse of the arms from behind towards the front top.

Air phase:

It is identified with the continuation of the upper limb that carries the body to assume an arched position, in order to obtain a "stretched" (abdominal and pectoral above) and a consequent greater development of strength transferable on the balloon. The movement of the arm must be such as to allow hitting the ball at the highest point possible; the arm that does not attack rises first in the direction of the ball, the one that attacks performs a load to the top behind.

Hit on the ball and its heights reached from knee and hand:

Action that the hand performs at the moment of contact with the ball and which may be gender:

- Crushed: the hand acts in order to cause an increase in speed by raising "whip" of the wrist.

- Lob: the shot is made only touching the ball with the fingers that are slightly open.

- Damped: differs from crushed as the final movement of the arm is voluntarily slowed down.

- Contrast: is a very particular type of attack, almost at the limit of the regulation; may be useful in the case in which the ball is particularly close to the opposing wall and is carried out by pushing with force the ball against the hands of the wall.

Relapse on the ground:

It is possible to make it less traumatic. This should be done on both toes at the same time. Following the damping action is completed thanks to a slight knee bend.

Tool

To analyze the whole, the instrument used is the software Kinovea.

Kinovea is a free software and open source solution for video analysis. It is mostly used by sports coaches and trainers to study or comment a performance. The Kinovea video controls allow you to focus on a specific action in the video and explore the structure of the movement, frame by frame or in slow motion. In addition, the drawing tools to enrich the video with the addition of arrows, descriptions and other content for key images. Tools and online stopwatch to measure distance and time. A semi-automatic plotting instrument allows to follow the path of a point, or of a body, in order to calculate the trajectory and, consequently, the distance traveled or the speed expressed.

\section{RESULTS AND CONCLUSIONS}

The results will be useful for identifying the errors and to analyze the causes, to suggest different ways of analysis and self-analysis of technical movements for educational purposes, and also for a hypothetical different way to teach specific technical gestures, using video feedback. It is expected that the performance analysis proposed as video at the beginning of training, for the experimental group B, improve athletes' technique quickly and with less time than group $A$ control. It will also be useful to compare this project with the previous one, to see if there are substantial differences between the learning of motor gestures between male athletes and female athletes, and possibly lay the groundwork for a subsequent step of research. 


\section{REFERENCES}

1. HUGHES MD, FRANKS IM. Essentials of Performance Analysis. London: E. and F.N. Spon. 2008.

2. HUGHES M, ROBERTSON C. Using computerised notational analysis to create a template for elite squash and its subsequent use in designing hand notation systems for player development. In: Lees A, Maynard I, Hughes M, Reilly T (eds), Science and Racket Sports II. London: E. and F.N. Spon. 1998: 227-234.

3. RAIOLA G, DI TORE P. Statistical study on bodily communication skills in volleyball to improve teaching methods. Journal of Human Sport and Exercise. 2012; 7(2): 468-488.

4. RAIOLA G, DI TORE P. Bodily communication skills and its incidence on female volleyball championship to enhance didactics. Journal of Human Sport and Exercise. 2012; 7(2): 365-375. 